\title{
Examination of Surface Roughness on Abrasive Water Jet Machining of Carbon Epoxy Composite
}

\author{
M. Uthayakumar, S. Vigneshwaran, K. Shankar, R. Balasubramani, R. Venkatesan
}

\begin{abstract}
The main aim of this investigation is to study the surface roughness produced on abrasive water jet machining of the twill weaved carbon fibre reinforced epoxy composite. Abrasive water jet machining experiment was conducted as per $L 9$ orthogonal array, by varying water pressure, transverse speed and SOD. The performance of the composite was analysed by measuring the surface roughness. Using Taguchi analysis, the influences of input parameter over the output response was analysed. It was found that the surface roughness is highly influenced by the transverse speed.
\end{abstract}

Keywords : Abrasive water jet machining, carbon fiber, epoxy, surface roughness.

\section{INTRODUCTION}

Com omposites are materials comprising of at least two particular constituents. Carbon fibre reinforced polymer composite (CFRP) is solid and light fiber-strengthened plastic which contains carbon filaments. CFRPs are costly however are normally utilized wherever high strength and unbending nature are required, for example in aviation, car, structural designing, sports products. Abrasive water jet machining is now presently used in various metal cutting process. The Abrasive Water Jet (AWJ) machining parameters such as jet operating water pressure (WP), transverse speed (TS), Standoff Distance (SOD), and concentration of abrasive are important for controlled cutting operation [1]. The quality of machining can be improved by controlling the AWJM parameters [2]. Water jet technology at present increasingly being used in a variety of applications including mining, process, medical and for machining of difficult-to-cut materials like composites, super alloys, rocks and ceramics [3]. In AWJ cutting of Fibre Reinforced Composites (FRCs), the kerf quality and finish produced are usually poor, necessitating finishing operations leading to further delamination [4]. Optimized machining can improve the quality of the cut during AWJM [5]. SOD is the most influencing parameter in affecting the kerf and surface

Revised Manuscript Received on December 30, 2019.

* Correspondence Author

M. Uthayakumar*, Faculty of Mechanical Engineering, Kalasalingam Academy of Research and Education, Srivilliputhur, India. Email: m.uthayakumar@klu.ac.in

S. Vigneshwaran, Faculty of Mechanical Engineering, Kalasalingam Academy of Research and Education, Srivilliputhur, India. Email: vigneshwaran.s@klu.ac.in

K. Shankar, R. Balasubramani, R. Venkatesan, Students, Department Education, Srivilliputhur, India. of Mechanical Engineering, Kalasalingam Academy of Research and

roughness [6]. The present article investigates on mechanism of surface roughness $(\mathrm{Ra})$ formed in abrasive water jet machining of carbon epoxy composite. In the present study, four process parameters of abrasive water jet machining namely hydraulic pressure, traverse rate, stand-off distance, and abrasive mass flow rate are considered. Analysis of variance (ANOVA) is performed in-order to investigate the influence of process parameters on surface roughness.

\section{MATERIALS AND METHODS}

\section{A. Material used and composite fabrication}

Carbon fibres in mat form was selected as reinforcement. The carbon fiber mat is twill weaved (2/2) with fiber orientation of $0 / 90^{\circ}$. Epoxy LY 556 is the resin which is used as the matrix material. For the present work carbon epoxy composite was fabricated using compression moulding process. The fiber mat was placed over the mild steel mould having size $175 \times 125 \times 10 \mathrm{~mm}$. The selected epoxy resin and hardener were mixed in suitable proportion as recommended by the supplier. The resin mixture is then poured over the reinforcement placed on the mould cavity and rolled by a roller to avoid air traps. Finally, mould was closed with the matching die and compressed at $5 \mathrm{MPa}$ pressure and left to cure for 24hours at room temperature. Both the mould and matching die was applied with the releasing agent for easy removal of the fabricated composite plate. The fabricated composite plates were shown in Figure 1.

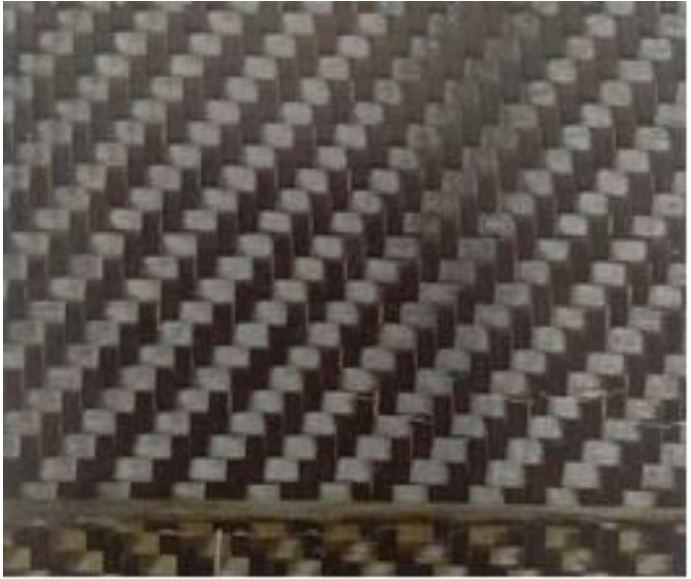

Fig. 1. Fabricated carbon fibre composite 


\section{B. Abrasive water jet machining}

The carbon epoxy composites were machined using Abrasive water jet machine DIPS6D-2230 supplied by The Dardi International. The experiment arrangement is shown in Figure 2. The abrasive used in the present experiment was Garnet of size 80 mesh. The mass flow rate of the abrasive particle was maintained constant between 2 to $3 \mathrm{~g} / \mathrm{s}$. Using AWJM a straight linear cut of $25 \mathrm{~mm}$ length as shown in Figure 3 was made on the hybrid composite by varying the three input parameters water pressure, stand-off distance and transverse speed. For the present experimentation work Taguchi L9 orthogonal array was selected for conducting the experiment. The surface roughness $(\mathrm{Ra})$ formed on the cut surface was measured using Mitutoyo SJ-301 profilometer. The probe in the profilometer moves over the cut surface through the length of $8 \mathrm{~mm}$ in transverse direction at the speed of $0.5 \mathrm{~mm} / \mathrm{s}$. The experiment results were shown in Table 1 .

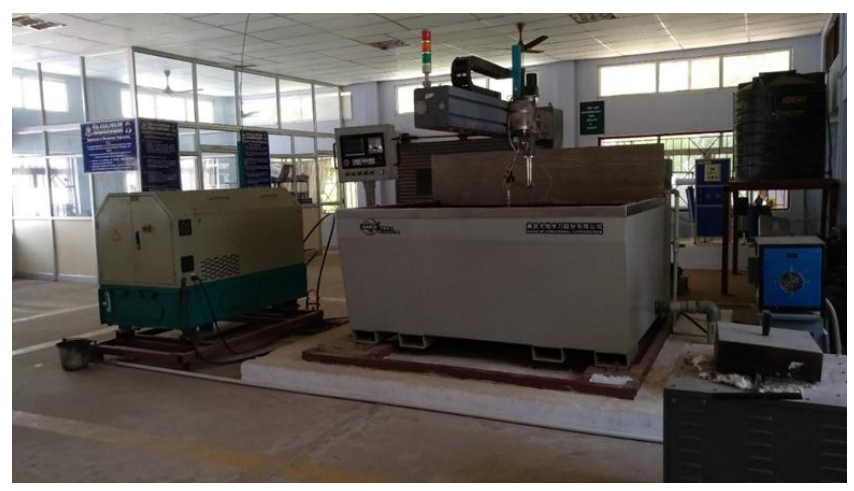

Fig. 2. Abrasive water jet machine

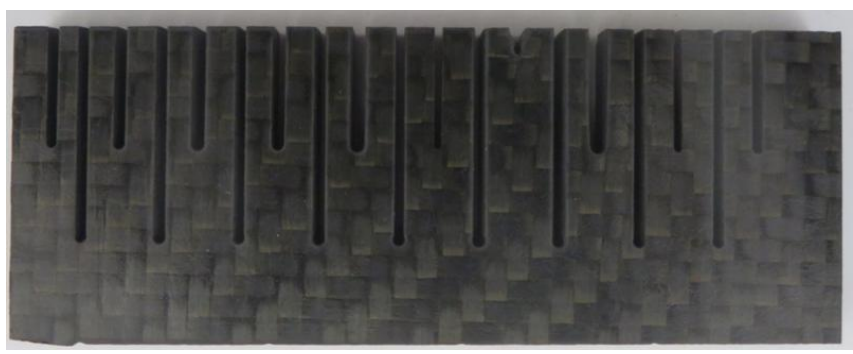

Fig. 3. Carbon fibre after L9 cutting

Table- I: AWJM Parameters and levels

\begin{tabular}{|l|l|l|l|l|}
\hline $\begin{array}{l}\text { Experiment } \\
\text { No }\end{array}$ & $\begin{array}{l}\text { Water } \\
\text { pressure } \\
(\mathbf{M P a})\end{array}$ & $\begin{array}{l}\text { TS } \\
(\mathbf{m m} / \mathbf{m i n})\end{array}$ & $\begin{array}{l}\text { SOD } \\
(\mathbf{m m})\end{array}$ & $\begin{array}{l}\text { Ra } \\
(\boldsymbol{\mu m})\end{array}$ \\
\hline 1 & 168 & 5 & 1 & 1.92 \\
\hline 2 & 168 & 15 & 2 & 2.19 \\
\hline 3 & 168 & 25 & 3 & 2.80 \\
\hline 4 & 216 & 5 & 2 & 2.12 \\
\hline 5 & 216 & 15 & 3 & 2.44 \\
\hline 6 & 216 & 25 & 1 & 2.44 \\
\hline 7 & 264 & 5 & 3 & 2.42 \\
\hline 8 & 264 & 15 & 1 & 2.71 \\
\hline 9 & 264 & 25 & 2 & 2.69 \\
\hline
\end{tabular}

The calculated surface roughness value was found to be scattering which is not followed any increasing or decreasing trend. This shows variation in cutting mechanism because of the non-homogeneous property of the composite. The variation in the fiber reinforcement in matrix and also the nature of fiber cutting mechanism were also the main reason for this.

The effect of AWJM variables on the Ra is shown in Figure 4 and 5. This is also evident from the ANOVA results shown in Table 2. The ANOVA analysis shows the significance of the three parameters affecting the Ra. F-value of water pressure, Transverse speed and SOD are 2.19, 4.85 and 1.18 respectively. It is noted that the Transverse Speed contributed $52.63 \%$ in affecting the Ra followed by the Water pressure $(23.72 \%)$ and SOD $(12.81 \%)$. The high influence of transverse speed on surface roughness is because at high TS the abrasive cut the surface more quickly which develop the uneven cut on the surface. Also at low TS the Ra value is minimum this evident that good surface finish can be obtained at lower TS.

Table- II: Ra ANOVA analysis

\begin{tabular}{|l|l|l|l|l|l|}
\hline Source & DF & Seq SS & Contribution & Adj SS & F-Value \\
\hline WP & 2 & 0.1627 & $23.72 \%$ & 0.1627 & 2.19 \\
\hline TS & 2 & 0.36103 & $52.63 \%$ & 0.36103 & 4.85 \\
\hline SOD & 2 & 0.08788 & $12.81 \%$ & 0.08788 & 1.18 \\
\hline Error & 2 & 0.07441 & $10.85 \%$ & 0.07441 & \\
\hline Total & 8 & 0.68602 & $100.00 \%$ & & \\
\hline
\end{tabular}

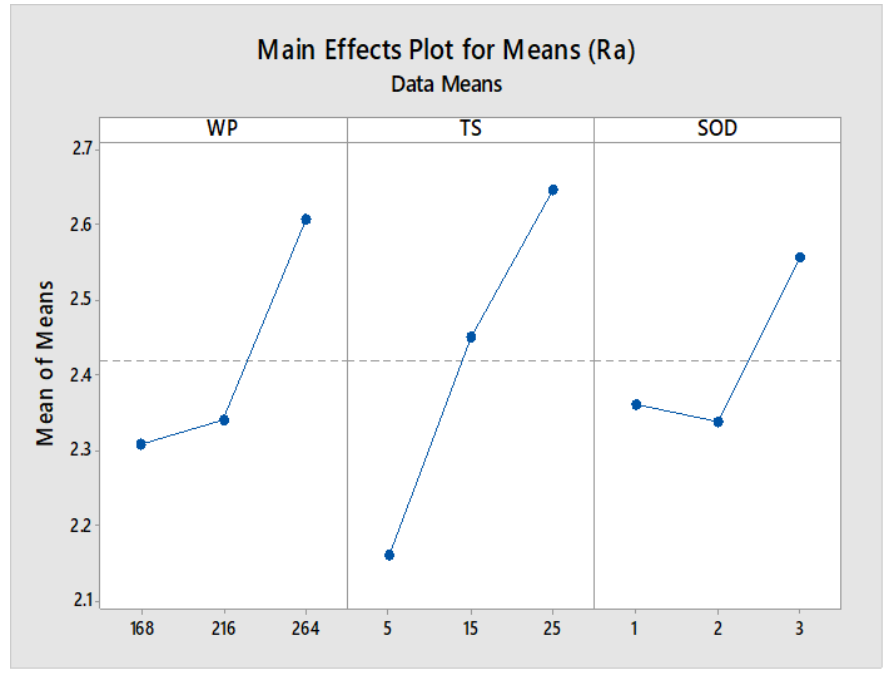

Fig. 4. Main effect plot for means (Ra)

\section{CONCLUSIONS}

Carbon fibre reinforced polyester composites were fabricated successfully. From the investigation of the fabricated composites the following results were concluded. The experiment results were analysed with Taguchi analysis. 
Transverse Speed contributed $52.63 \%$ in affecting the Ra followed by the Water pressure (23.72\%) and SOD (12.81\%). At low TS the Ra value is minimum this evident that good surface finish can be obtained at lower TS. The surface roughness values were found to be scattering due to the variation in the cutting mechanism.

\section{REFERENCES}

1. Dhanawade, Ajit, and Shailendra Kumar, "Experimental study of delamination and kerf geometry of carbon epoxy composite machined by abrasive water jet," Journal of Composite Materials, vol.51. pp. 3373-3390, 2017.

2. D. Doreswamy, D. Anjaiah, and N. Yagnesh, "An investigation of abrasive water jet machining on graphite/glass/epoxy composite," International Journal of Manufacturing Engineering, vol. 2015, pp. 11, 2015.

3. M. Haddad, R. Zitoune, F. Eyma and B. Castanié. "Influence of machining process and machining induced surface roughness on mechanical properties of continuous fiber composites," Experimental Mechanics, vol.55, pp.519-528, 2015.

4. Siddiqui, T. Uddin, M. Shukla, and Pankaj B. Tambe, "Comparative investigation of abrasive waterjet cut kerf quality characteristics for aramid, glass and carbon fiber reinforced composites used in transport aircraft applications," Proceedings of the 2009 American WJTA Conference, Houston, Texas. 2009.

5. Bhowmik, Sumit, and Amitava Ray. "Prediction and optimization of process parameters of green composites in AWJM process using response surface methodology," The International Journal of Advanced Manufacturing Technology, vol.87, pp.1359-1370, 2016.

6. V.Arumugaprabu, S. Thirumalai, and M. Uthayakumar, "Performance evaluation of abrasive water jet machining on banana fiber reinforced polyester composite."Journal of natural fibers, vol.14, pp.450-457, 2017.

\section{AUTHORS PROFILE}

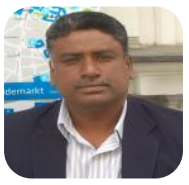

Dr. M. Uthayakumar has obtained Master of Engineering in Production Engineering from Thiagarajar College of Engineering (Autonomous), Madurai, India and Doctorate from Department of Production Engineering, National Institute of Technology, Tiruchirappalli. He has published 145 papers in the international journals and conference. Currently he is a Professor at Department of Mechanical Engineering, Kalasalingam Academy of Research and Education, Krishnankoil, Virudhunagar Dist.

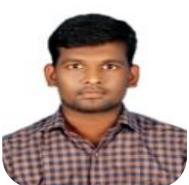

Mr. Vigneshwaran is a research scholar at Kalasalingam Academy of Research and Education, India. His area of interest includes polymer composites, composite machining and tribology. 